\title{
46.2354
}

\section{Analytical Methods for}

Fissionable Materials in the Nuclear Fuel Cycle Program Status Report June 1971 to June 1972

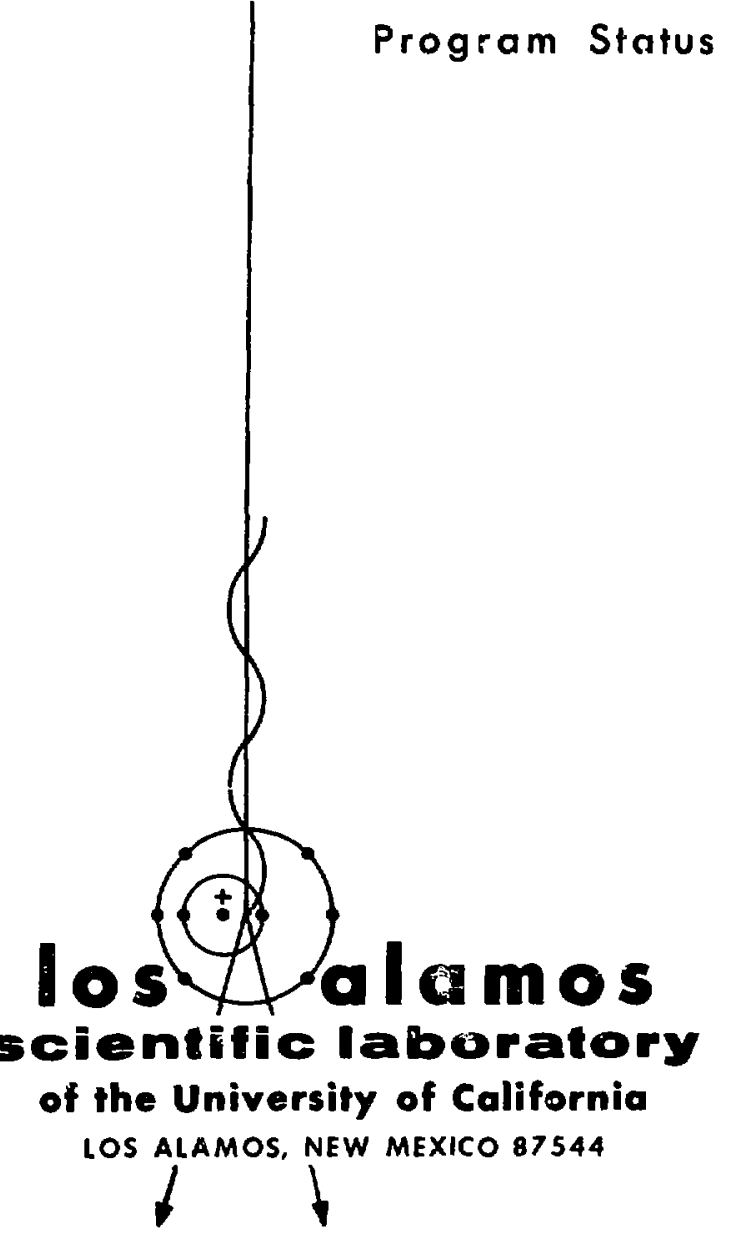


This report was prepared as an account of work sponsored by the United States Government. Neither the United States nor the United States Atomic Energy Commission, nor any of their employees, nor any of their contractors, subcontractors, or their employees, makes any warranty, express or implied, or assumes any legal liability or responsibility for the accuracy, completeness or usefulness of any information, apparatus, product or process disclosed, or represents that its use would not infringe privately owned rights.

In the interest of prompt distribution, this status report was not edited by the Technical Information staff.

Printed in the United States of America. Available from National Technical Information Service

U. S. Department of Commerce

5285 Port Royal Road

Springfield, Virginia 22151

Price: Printed Copy \$3.00; Microfiche $\$ 0.95$ 


\title{
Analytical Methods for
}

\section{Fissionable Materials in the Nuclear Fuel Cycle}

\author{
Program Status Report June 1971 to June 1.972
}

\author{
Compiied by
}

\section{Glenn R. Waterbury}

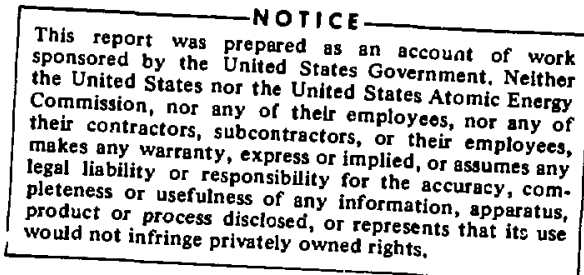

This work performed under the auspices of the U. S. Atomic Energy Commission's Division of Nuclear Materials Security. 


\section{CONTENTS}

Dissolution and Gamma Counting Analysis of Fuel Cycle Materials . . . . . . . . . . . Page

Automated Apparatus for the Determination of Uranium and Plutonium . . . . . . . . . . 5

Plutonium-Containing Materials for the SALE Program . . . . . . . . . . . . . . . 8

Plutonium Metal Chemical Standards . . . . . . . . . . . . . . . . . . . . 9 


\section{ANALYTICAL METHODS FOR FISSIONA BLE MATERIALS IN THE NUCLEAR FUEL CYCLE \\ Compiled by \\ Glenn R. Waterbury}

\section{A BSTRACT}

Progress is reported on the development of analytical methods for the determination of uranium and plutonium for nuclear safeguards application and the preparation of well-characterized plutonium-containing materials for laboratory evaluation purposes and as standards. A Teflon-container, metal-bomb apparatus has been developed for the dissolution of samples in acids, including hydrofluoric acid, at temperatures to $280^{\circ} \mathrm{C}$ and pressures to 5000 psi. Apparatus and conditions have been developed for assay of small amounts of ${ }^{235} \mathrm{U}$ by gamma counting with a NaI(T1) detector. This system is being extended to the assay of ${ }^{239} \mathrm{Pu}$.. The development of an automated apparatus is nearing completion for the determination of $u_{\text {ranium }}$ and plutonium by a selective extraction of these actinides into an organic phase and a spectrophotometric measurement of the extracted species in the organic phase. Samples of plutonium nitrate solution in sealed glass ampoules with measured plutonium contents and isotopic compositions were prepared for the Safeguards Analytical Laboratory Evaluation Program. One lot of highly pure plutonium metal chemical standards was prepared for shipment to the National Bureau of Standards.

The major objectives of this program are: (1) the development of fast dissolution techniques and analytica. methods for the determination of $U$ and Pu with emphasis on scrap-type and difficult-todissolve materials, (2) the automation of analytical methods for the determination of $U$ and $P u,(3)$ the preparation of well-characterized plutonium-containing materials for use in the Safeguards Analytical Laboratory Evaluation (SALE) Program, and (4) the preparation of well-characterized, highpurity $\mathrm{Pu}$ metal chemical standards for distribution by the National Bureau of Standards (NBS).

Dissolution and Analysis of Fuel Cycle Mrateria1s (G. C. Swanson, R. M. Ortíz, J. E. Rein)

Of prime interest in the chemical characterization of nuclear fuel cycle materials are measurements of their $U$ and Pu contents. The materials include nonuniform scrap and mixtures of highly refractory compounds. The past general philosophy for analyzing these materials has been total dissolution followed by highly precise chemical analyses. The use of methods that are less time consuming is an economic necessity with the ever-increasing numbers and types of materials, many of which are heterogeneous.

An assay method now being developed uses a relatively fast dissolution of $90 \%$ or more of the $U$ and $P u$, which are determined by chemical analysis, and a gamma counting analysis of the residue fraction for these elements. The overall relative standard deviation of these measurements is no greater than $1.5 \%$ when the relative standard deviations of the chemical method and gamma courting measurement are $1 \%$ and $10 \%$, respectively.

In the past year, a dissolution apparatus has been developed consisting of a Teflon container in a metal bomb. This apparatus (Fig. 1) permits use of a variety of acid mixtures at temperatures to $280^{\circ} \mathrm{C}$ and pressures to $5000 \mathrm{psi}$. An inexpensive gamma counting apparatus, used under conditions that were developed, is adequate for the determination of ${ }^{235} \mathrm{U}$ and ${ }^{239} \mathrm{Pu}$ in the undissolved residues with a relative standard deviation no greater than $5 \%$. In testing this method and equipment, several refractory fuel mixtures were partially dissolved, the $U$ in the dissolved fraction 


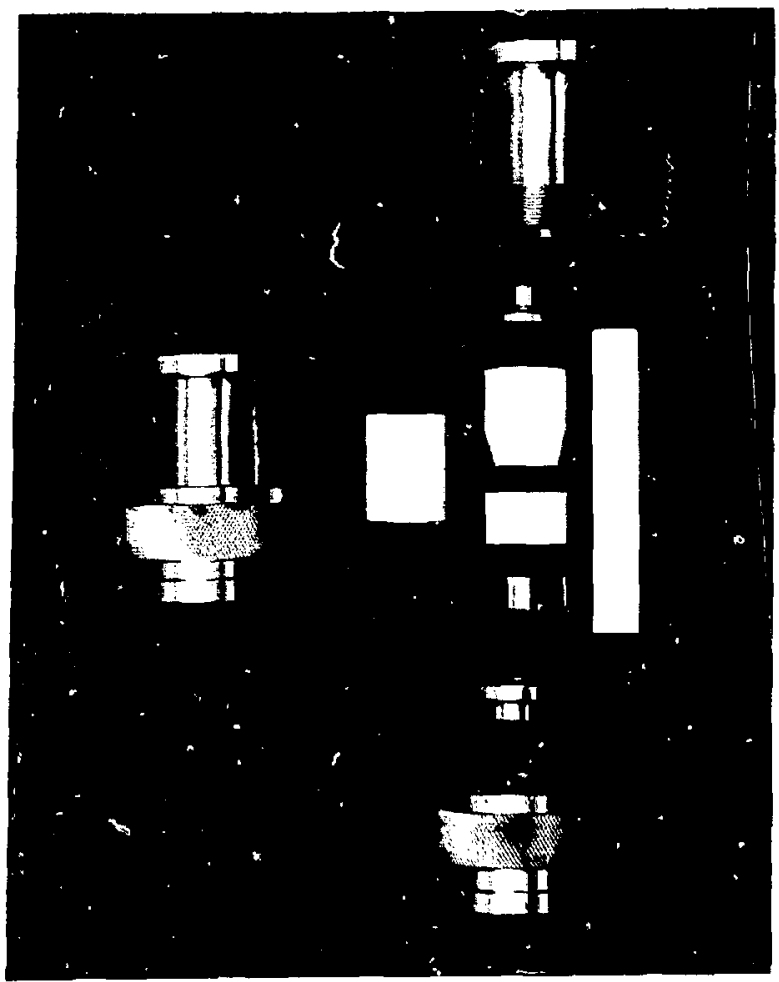

Fig. 1. Components of the Teflon Container and Meial Bomb.

was measured by a rapid spectrophotometric method, and the undissolved residue was assayed for $U$ by gamma counting. The overall relative standard deviation was less than $1.5 \%$ for each sample. The spectrophotometric method is being automated as described in the next section.

The operational basis of the Teflon-container, metal-bomb apparatus is similar to that of the sealed, fused-silica tube developed at the NBS ${ }^{(1)}$ and successfully used for many materials in this laboratory for the past 25 years. (2) Advantages of the Teflon-container, metal-bomb apparatus are the capability to use $\mathrm{HF}$ as a solvent, reusability of the Teflon container, and handling ease in the sealing and opening operations.

The metal bombs are machined from either 347 stainless steel or nickel 200 alloy. The Teflon container ${ }^{(3)}$ has a long taper to provide a tight seal. Spring tension applied to the lid of the Teflon container maintains the seal as the Teflon shrinks or contracts upon cooling. Containers fabricated from TFE Teflon (Trademark, E. I. Du Pont de Nemours, Inc. ) have been reused up to twenty times although they slowly and irreversibly shrink from an initial volume of $30 \mathrm{cc}$ to a final volume of approximately $10 \mathrm{cc}$.

The reason for using two metals for the bombs is to resist corrosion by acid vapors that diffuse through the Teflon containers at the operating temperature. Corrosion is slight for the 347 stainless steel bomb when used with concentrated $\mathrm{HNO}_{3}$, $\mathrm{H}_{2} \mathrm{SO}_{4}, \mathrm{HNO}_{3}-\mathrm{H}_{2} \mathrm{SO}_{4}$ mixtures, or $\mathrm{HNO}_{3}-\mathrm{H}_{2} \mathrm{SO}_{4}-$ HF mixtures. The nickel bomb is used for concentrated $\mathrm{HF}$ or $\mathrm{HCl}$ and $\mathrm{HF}-\mathrm{HCl}$ mixtures with or without small amounts of oxidizing acids. The metal bombs have raised bands at the ends that are designed to ride on a revolving track in the furnace, if desired, to improve mixing and thereby speed dissolution. A custom-fabricated oven has just been received for use in a glove box in the dissolution of plutonium-containing materials.

Results of dissolution studies in the Tefloncontainer, metal-bombs apparatus for several uranium-containing refractory materials are summarized in Table I. For purposes of comparison, dissolution treatments with various acid mixtures were made in Teflon dishes and in a glass, reflux apparatus at ambient pressure. The percentage of $U$ dissolved was computed from chemical analyses of the filtered solutions and gamma counting of the residues for ${ }^{235} \mathrm{U}$. The isotopic composition of each material was accurately determined by thermal-ionization, mass spectrometry to provide data to calculate total uranium weight in both analyses. In general, the time of reaction for all three systems was from 12 to $24 \mathrm{~h}$. For some materials, the use of $\mathrm{HF}$ in a Teflon dish dissolved as much $U$ as did the bombs. The bombs, however, had the advantage of total containment without spattering losses.

The operational pressure limit of the bombs is 5000 psi. Although the various acid mixtures generate pressures of 3000 psi or less at $280^{\circ} \mathrm{C}$, additional pressure can be produced by gases formed from the chemical reactions of the acids with samples. To measure these potentially high total pressurcs, a rather massive bomb was constructed for operation to 10,000 psi with a continuous pressure readout. The same Teflon container was used in this bomb as in the 5000 psi bomb. Pressure 
TA BLE I

\section{DISSOLUTION OF URANIUM-CONTAINING}

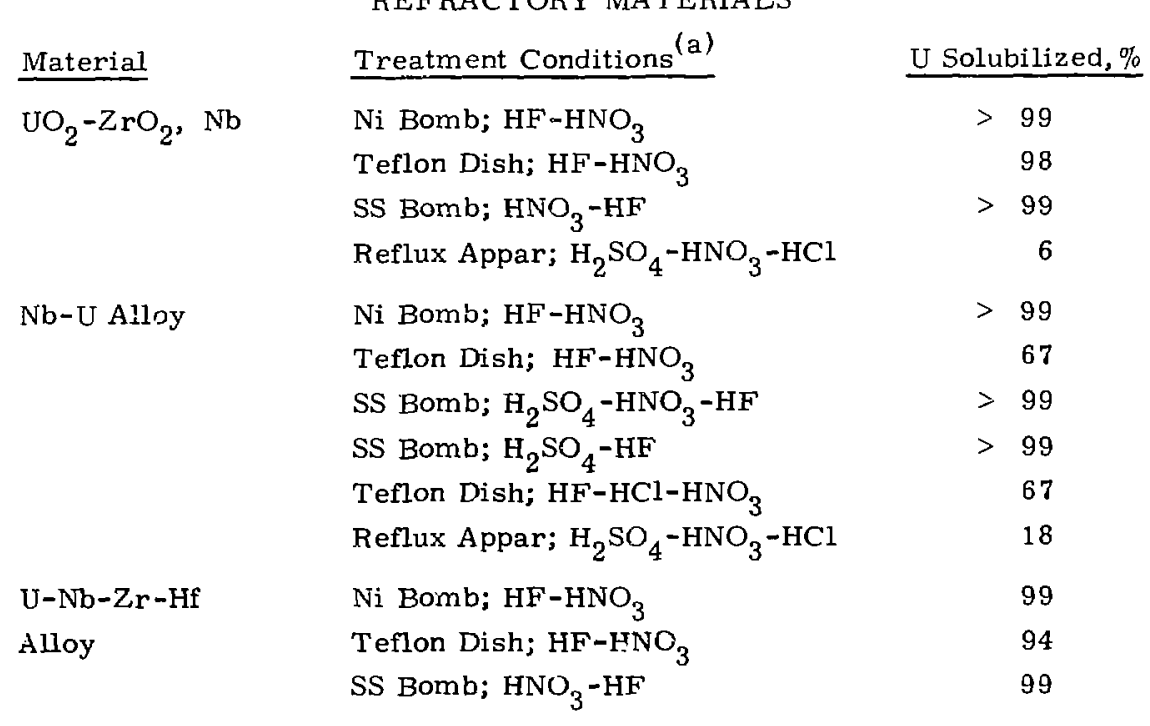

(a) All bombs had Teflon containers and were operated at $275^{\circ} \mathrm{C}$. All acids were concentrated. Reaction times were 12 to $24 \mathrm{~h}$. The acid that was present in the largest concentration is listed first.

readout was accomplished via a Teflon diaphragm and silicone oil to an electromechanical transducer. The pressure readout was calibrated by heating water in the bomb at various temperatures. The slow attainment of thermal equilibrium of this large bomb limited output to about one experiment per week. Each proposed acid mixture-sample combination was first tested in the 10,000 psi bomb.

The major criteria governing the gamma counting system for analyzing residues were low apparatus cost, operational simplicity, low maintenance, high count rates for speed of analysis, measurement of ${ }^{235} \mathrm{U}$ and ${ }^{239} \mathrm{Pu}$ rather than any other isotopes, and a relative standard deviation no greater than $10 \%$. To meet these criteria, a NaI(T1) detector coupled to a single channel analyzer was used. The ${ }^{235} \mathrm{U}$ and ${ }^{239} \mathrm{Pu}$ were selected for determination because they are the major fissionable isotopes in most nuclear fuel cycle materials, and hence, most iniportant from the safeguards standpoint. The conversion to total $\mathrm{U}$ requires isotopic abundances usually measured routinely by mass spectrometry for all materials analyzed for safeguard purposes.
The residues remaining from dissolution are collected on a $0.25-\mu$-pore-size, plastic-membrane filter, the filter chimney is rinsed with acid similar to that used for dissolution, vacuum is applied to air-dry the residue, and the filter with residue is mounted on an aluminum counting plate with a cellophane tape covering. The $185 \mathrm{-keV}$ gamma photopeak of ${ }^{235} \mathrm{U}$ is counted using a window of 153 to $245 \mathrm{keV}$.

A series of nine calibration standards was prepared from fully enriched and stoichiometric $\mathrm{U}_{3} \mathrm{O}_{8}$ and mounted as were the samples. The standards cover the range of 2.50 to $30.0 \mathrm{mg}{ }^{235} \mathrm{U}$. The average calibration factor for the nine standards is $5.16 \mathrm{c} / \mathrm{s} / \mathrm{mg}^{235} \mathrm{U}$ with a relative standard deviation (for a single measurement) of $3.9 \%$. Additional calibration standards are being prepared from highly pure; fully enriched and low enrichment ${ }^{235} \mathrm{U}$ metals. These standards will be used to establish the effect of Compton contributions from the ${ }^{238} \mathrm{U}$ and daughters on the $185-\mathrm{keV}$ gamma response.

As the $185-\mathrm{keV}$ photon is attenuated by high $Z$ elements, including $U$ itself, sample self-absorption is determined and an appropriate correction is 


\begin{tabular}{|c|c|c|c|}
\hline$I / I_{0}^{(a)}$ & Correction Factor $(b)$ & $\mathrm{I} / \mathrm{I}_{\mathrm{O}}^{(\mathrm{a})}$ & Correction Factor ${ }^{(b)}$ \\
\hline 0.99 & 1.0050 & 0.85 & 1.0834 \\
\hline 0.98 & 1.0101 & 0.84 & 1.0897 \\
\hline 0.97 & 1.0153 & 0.83 & 1.0960 \\
\hline 0.96 & 1.0205 & 0.82 & 1.1024 \\
\hline 0.95 & 1.0259 & 0.81 & 1.1090 \\
\hline 0.94 & 1.0312 & 0.80 & 1.1157 \\
\hline 0.93 & 1.0367 & 0.79 & 1.1225 \\
\hline 0.92 & 1,0423 & 0.78 & 1.1293 \\
\hline 0.91 & 1.0479 & 0.77 & 1.1364 \\
\hline 0.90 & 1.0536 & 0.76 & 1.1434 \\
\hline 0.89 & 1.0594 & 0.75 & 1.1506 \\
\hline 0.88 & 1.0653 & 0.74 & 1.1579 \\
\hline 0.87 & 1.0712 & 0.73 & 1.1655 \\
\hline \multirow[t]{3}{*}{0.86} & 1.0772 & 0.72 & 1. 1732 \\
\hline & & 0.71 & 1.1809 \\
\hline & & 0.70 & 1.1888 \\
\hline
\end{tabular}

(a) Ratio of $\mathrm{c} / \mathrm{s}$ for $235 \mathrm{U}$ metal foil through sample relative to no sample.

(b) Multiply by this factor to correct the measured $\mathrm{c} / \mathrm{s}$ for matrix absorption.

applied. This correction is obtained by counting a ${ }^{235} \mathrm{U}$ metal foil by itseif, then through the sample. The computation of the absorption correction factor, given in Table $\Pi$, assumes that the ${ }^{235} U$ in the mounted sample residue is uniformly distributed in a homogeneous matrix.

The desired gamma energy region to be counted for ${ }^{239} \mathrm{Pu}$ is above $340 \mathrm{keV}$ where there are no significant peaks of other plutonium isotopes or their decay chain daughters. In an initial evaluation to establish the settings for the single channel analyzer, two sets of nine plates each were prepared from weighed quantities of two different $\mathrm{PuO}_{2}$ powders and these plates were counted using a $\mathrm{Ge}(\mathrm{Li})$ detector ccupled to a multichannel analyzer. The $\mathrm{PuO}_{2}$ powders had different plutonium isotopic compositions and the ${ }^{241} \mathrm{Am}$ contents were 400 and $3500 \mathrm{ppm}$, respectively. For the range of 375 to $415 \mathrm{keV}$, the average $\mathrm{d} / \mathrm{s} / \mathrm{mg}{ }^{239} \mathrm{Pu}$ differed by $21 \%$ for the two $\mathrm{PuO}_{2}$ powders. The energy window of the analyzer system then was adjusted to equalize the $\mathrm{c} / \mathrm{s} / \mathrm{mg}$ ${ }^{239} \mathrm{Pu}$ for both powders. This adjusted window was
402 to $472 \mathrm{keV}$ and the relative standard deviation for the $\mathrm{c} / \mathrm{s} / \mathrm{mg}{ }^{239} \mathrm{Pu}$ for the 18 plates was $4.5 \%$.

To ensure that the count rates for this window setting are proportional only to ${ }^{239} \mathrm{Pu}$, three series of ten plates each were prepared from three, highly pure, Pu-metal samples, each with a different isotopic composition (Table III.) A weighed sample of each metal was dissolved in $\mathrm{HCl}$ and 10 weighed aliquots containing 0.5 to $30 \mathrm{mg}$ of Pu were evaoorated to dryness on aluminum counting plates.

The $\mathrm{Ge}(\mathrm{Li})$ and the $\mathrm{Na} \mathrm{I}(\mathrm{Tl})$ gamma spectra obtained with a 0.030-in. cadmium absorber for these three plutonium samples are presented in Fig. 2. In the Ge(Li) spectra, all peaks except the 332. 3-keV sum peak are ${ }^{239} \mathrm{Pu}$ peaks. The out.standing difference among these spectra is the $332.3-\mathrm{keV}$ peak caused mainly by the activity of 6. 75-day ${ }^{237} \mathrm{U}$, in equilibrium with its ${ }^{241} \mathrm{Pu}$ parent. This peak distorts the Na I(Tl) spectra at the ${ }^{239} \mathrm{Pu}$ peak of $375.0 \mathrm{keV}$. In order for the gamma counts to be a direct measure of the ${ }^{239} \mathrm{Pu}$ with a $\mathrm{Na} \mathrm{I}(\mathrm{Tl})$ detector system, it is necessary to 
TABLE III

ISOTOPIC COMPOSITION OF PLUTONIUM METAL SAMPLES

\begin{tabular}{|c|c|c|c|}
\hline Isotope & $\begin{array}{l}\text { Atom } \\
\text { A }\end{array}$ & $\begin{array}{c}\text { Percent, for } \\
\mathrm{B}\end{array}$ & Pu Sample \\
\hline 238 & 0.0128 & 0.0180 & 0.0040 \\
\hline 239 & 83.189 & 93.932 & 97.620 \\
\hline 240 & 15.154 & 5.692 & 2.320 \\
\hline 241 & 1.402 & 0.337 & 0.054 \\
\hline 242 & 0.242 & 0.020 & 0.003 \\
\hline
\end{tabular}

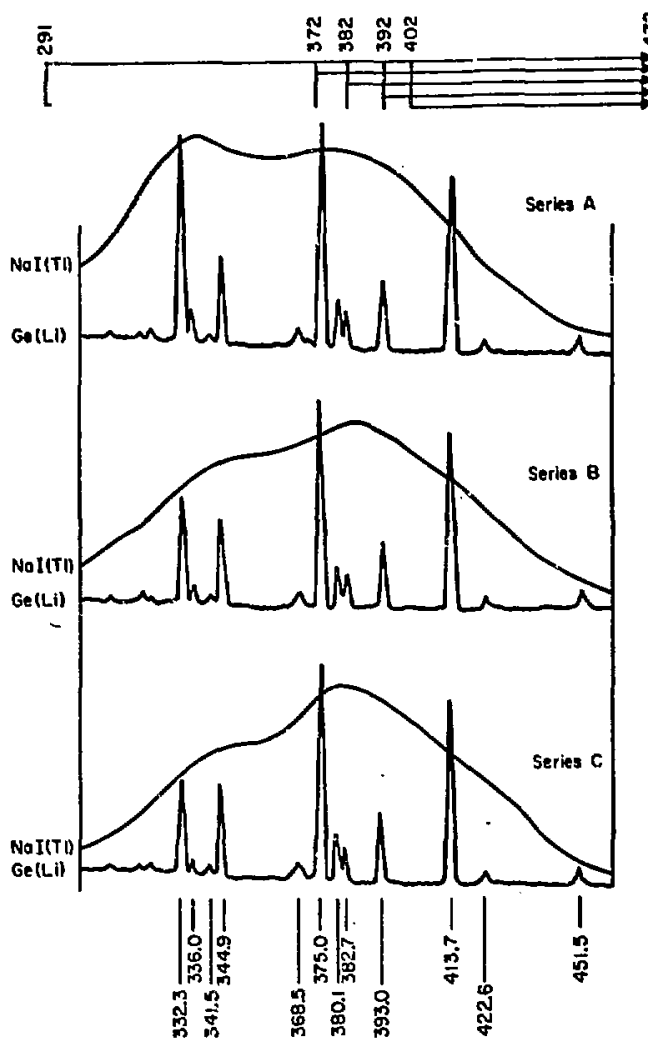

Fig. 2. Ge(Li and NaI(T1) Spectra of Three Pu Metal Samples

set the low energy cutoff of the single channel window at an energy level which must be determined for each detector-counting system. For the system in use, the high energy cutoff value was set at $472 \mathrm{keV}$, the low energy cutoff value was varied as shown at the top of Fig. 2, and the plates containing the three series of $\mathrm{Pu}$ materials were counted (Talıie IV). The effect from the $332.3-\mathrm{keV}$ peak of ${ }^{237} \mathrm{U}$ becomes negligible at a low energy cutoff near $392 \mathrm{keV}$. By setting the low energy cutoff at $392 \mathrm{keV}$, the gamma count rate is a direct measure of ${ }^{239} \mathrm{Pu}$, and the sensitivity loss is only threefold compared to a low energy cutoff of 291 $\mathrm{keV}$. The relative standard deviation (for a single measurement) for the integrated $\mathrm{c} / \mathrm{mg}^{239} \mathrm{Pu}$ computed for all 30 plates is 3\%. The recorded inte grated counts ranged from about 700 for the plates with $0.5 \mathrm{mg}$ of $\mathrm{Pu}$ to about 70,000 for the plates with $30 \mathrm{mg}$ of $\mathrm{Pu}$.

The higher gamma energy range that is used for counting of plutonium residues, as compared to counting of ${ }^{235} \mathrm{U}$ residues, makes sample absorption effects insignificant. For example, at a $\mathrm{Pb} / \mathrm{Pu}$ ratio of $32 / 1$, obtained with a mixilire of $\mathrm{PbO}$ and $\mathrm{PuO}_{2}$ powder, the ${ }^{239} \mathrm{Pu}$ gamma attenuation is less than $1 \%$ for the 392 -to $472-\mathrm{keV}$ window. There is no need, therefore, to count a standard foil through the residue to obtain an absorption correction as there is for the ${ }^{235} \mathrm{U}$ analysis.

Automated Apparatus for the Determination of Uranium and Plutonium

(D. D. Jackson, D. J. Hodgkins, J. E. Rein)

The mechanical portion of the prototype instrument for the automated determination of $\mathrm{U}, \mathrm{Pu}, \mathrm{or}$ their simuitaneous determination using an extraction-spectrophotometric method $(4,5)$ has been constructed and satisiactorily tested. In the instrument, a 20-in. -diam turntable holds 18 sample tubes and rotates them into position for each operation. The maximum size of the instrument was established by the requirement that it fit into a Lf.SL-type glovebox that is 36-in. wide, 31-in. deep, and 33-in. high with a sloping front. By using a drive mechanism with a different angular rotation per movement, the capacity will be increased to 24 samples on the operational model to be constructed next fiscal year for possible use by the AEC New Brunswick Laboratory. The time required for analysis of 18 samples is $1.5 \mathrm{~h}$ and is expected to be $2 \mathrm{~h}$ for 24 samples in the operational model.

An extraction-spectrophotometric: method was selected because it involved few operations and was highly selective for $U$ and $F u$. The major. operational steps are (1) addition of $\mathrm{Al}\left(\mathrm{NO}_{3}\right)_{3}$ salting solution containing tetrapropylammoniun nitrate to form a complex containing the $\mathrm{U}$ and/or 
GAMMA COUNTING RATES FOP THREE PLUTONIUM SAMPLES AS A FUNCTION OF ENERGY WINDOW

\begin{tabular}{|c|c|c|c|}
\hline $\begin{array}{c}\text { Energy Window } \\
\mathrm{keV}\end{array}$ & Pu Sample & $\mathrm{C} / \mathrm{S} / \mathrm{mg}^{239} \mathrm{Pu}$ & Rel Std Dev, $\%_{0}^{(a)}$ \\
\hline \multirow[t]{3}{*}{$291-472$} & $A$ & 6.026 & 2.4 \\
\hline & $\mathbf{B}$ & 5.004 & 3.0 \\
\hline & $\mathrm{C}$ & 4.854 & 1.2 \\
\hline \multirow[t]{3}{*}{$372-472$} & A & 3.020 & 1.3 \\
\hline & B & 2.984 & 2.9 \\
\hline & $\mathrm{C}$ & 2.752 & 4.3 \\
\hline \multirow[t]{3}{*}{$382-472$} & $A$ & 2.382 & 2.6 \\
\hline & B & 2.288 & 3.3 \\
\hline & $\mathrm{C}$ & 2.349 & 2.0 \\
\hline \multirow[t]{3}{*}{$392-472$} & $A$ & 1.976 & 5.0 \\
\hline & B & 1.934 & 1.7 \\
\hline & $\mathrm{C}$ & 1.955 & 2.5 \\
\hline \multirow[t]{3}{*}{$402-472$} & A & 1.486 & 2.1 \\
\hline & B & 1.447 & 3.4 \\
\hline & $\mathrm{C}$ & 1.472 & 4.2 \\
\hline
\end{tabular}

(a) Computed from the data obtained for the ten plates prepared for each sample.

$\mathrm{Pu}$, (2) addition of methyl isobutyl ketone (hexone) extractant, (3) mixing to extract the complex into the organic phase, (4) separation of phases, and (5) measurement of absorbance.

It was not possible to adapt this method to the Technicon Auto Analyzer continuous-flow system of analysis because the flexible tubing in the Technicon pumping system was not compatible with the organic extractant. Various flexible tubings, including samples supplied by Technicon, were tested and found to be unsatisfactory.

In the LASL instrument the samples are pipetted by hand into individual containers which then are placed in a turntable. The turntable sequentially rotates to stations where the various reagents are added and operational steps, including the measurement of absorbance, are done. With this instrument, the degredation of flexible tubing by organic solvents is avoided and pumping systems are not used. The major components of the instrument are: (1) the turntable, (2) dispensers for adding various reagents, (3) a magnetic mixer, (4) a filter spectrophotometer, and (5) the control mechanism for correct sequential operation.

Simple and economical sample containers are made from precision-bore, 0.75-in.-diam tubing to provide equal and precise light path lengths for optical measurements. This tubing diameter was the experimentally determined optimum which is a compromise to obtain efficient mixing of aqueous and organic phases, efficient phase disengagement, an adequate optical path length, and a small error in the effective optical path length caused by differences of positioning tubes in the Teflon-lined inserts of the turntable.

The 20-in. -diam turntable (Fig. 3) is rotated by a Geneva drive, intermittent-motion assembly which avoids rapid accelerations and provides reproducible rotational positioning. To ensure accurate positioning of the tubes, a tapered pin driven by a pneumatic cylinder engages a slot milled into the outer circumference of the turntable after each rotational increment. 


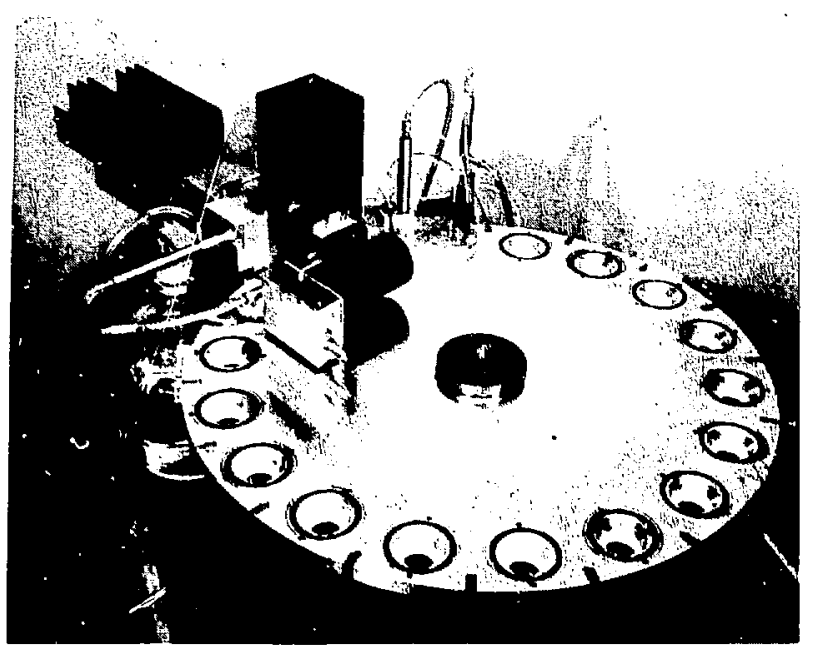

Fig. 3. Turntable of LASL Automatic Analyzer

The reagents are delivered by piston-displacement dispensers (Fig. 4) in which only glass, Teflon, and Kel-F contact the reagents. The pneumatichydraulic cylinder system developed to drive the syringes provides better delivery control than is obtained with pneumatic cylinders alone. A small 3 -way valve actuated by a pneumatic cylinder controls the flow of the reagents with high dependability. The relative standard deviation, determined by weighing dispensed quantities, was $0.02 \%$ for ten $4-$ $\mathrm{ml}$ deliveries of the viscous $\mathrm{Al}\left(\mathrm{NO}_{3}\right)_{3}$ salting solution and $0.09 \%$ for ten $3-\mathrm{ml}$ deliveries of hexone.

Extraction of the uranium complex into the organic solvent is accomplished by mixing for $4 \mathrm{~min}$ using a Teflon-covered, 1-in. long, 0.375-in. diam cylindrical stirring bar rotated by a revolving magnet (Fig. 5). The revolving magnet is positioned $0.5-i n$. above the bottom of the tube to provide efficient stirring action. To prevent interference with the rotation of the turntable by the revolving magnet, it is moved down when it is not in use to allow the tubes to pass over the magnet.

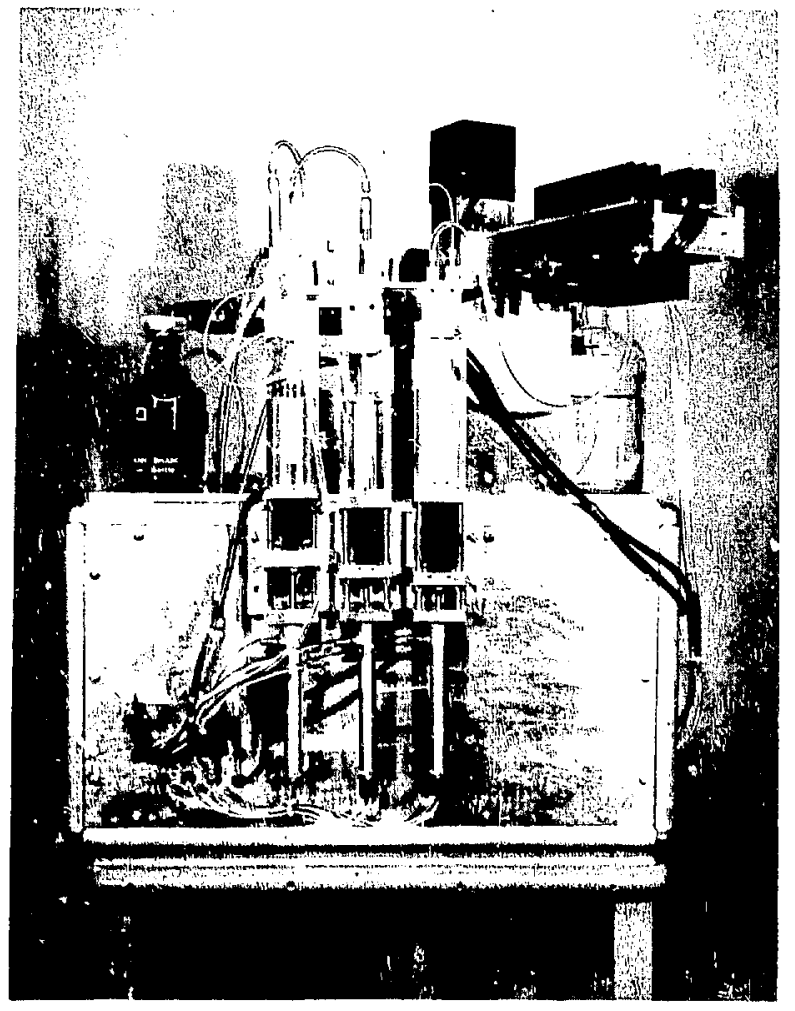

Fig. 4. Piston Displacement Reagent Dispensing System

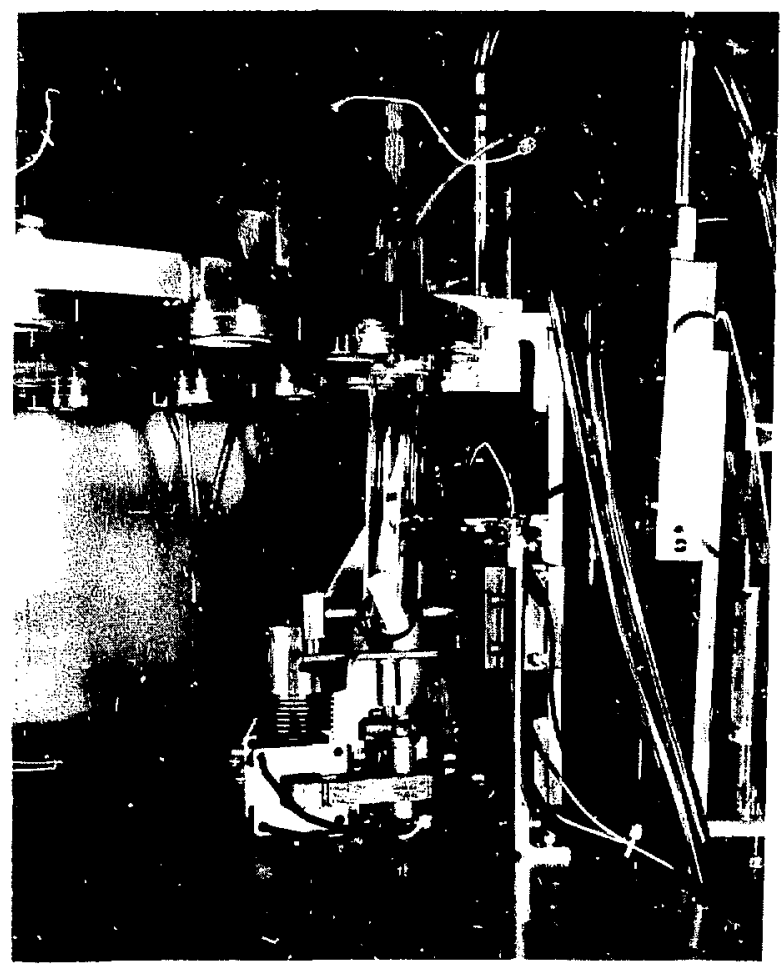

Fig. 5. Stirring Apparatus 
The phases disengage in about $1 \mathrm{~min}$. A 3-min standing period is programmed for this step to assure an optically clear organic phase. Before the a.bsorbance measurement, saturated $\mathrm{Al}\left(\mathrm{NO}_{3}\right)_{3}$ solution is added to the tube to raise the organic phase above the area of the tube where aqueous droplets might adhere.

A simple, rugged spectrophotometer, using narrow-bandpass interference filters as the monochromator (Fig. 6), measures the very sharp absorption peaks. To minimize variability from base-line shift, absorbances are measured at the pertinent peak and at a valley adjacent to this peak. The difference is used as a measure of the $U$ or $P u$. The wavelength of maximum absorbance for the $U$ complex is $452.5 \mathrm{~nm}$; the filters have peak transmissions at 452.3 and $460.3 \mathrm{~nm}$ with a bandpass width less than $1.4 \mathrm{~nm}$. The two filters are moved sequentially into the light path with a pneumatic cylinder for the

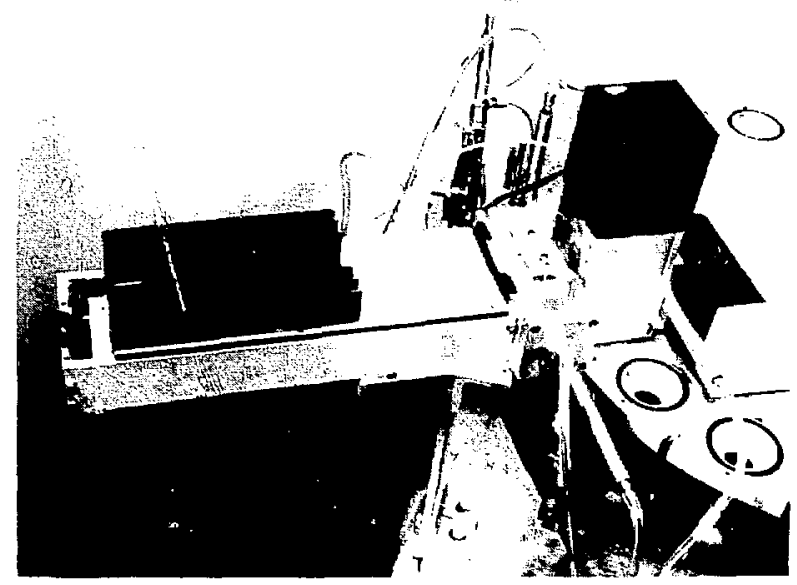

Fig, 6. Filter Spectrometer optical measurements. Two other interference filters will be used for the $\mathrm{Pu}$ determination. The light source is a $45-\mathrm{W}$ quartz iodine lamp powered by an electronically regulated dc-power supply to reduce rariability in the light and therefore in the measured absorbances. The detector is a $1 \mathrm{P} 21$ photomultiplier tube. Dark current is balanced by a counter current through a potentiometer from a $9-\mathrm{V}$ battery. The detector output is electronically converted to an absorbance readout as an output voltage. The sample tubes are raised by a pneumatic-hydraulic cylinder into a precisely held position and light baffles are automatically positioned to make the spectrophotometer chamber light tight.

Seven cams on a common motor-driven shaft control the sequence of operations required for delivery of reagents, moving the turntable, stirring, and control of the readout system. A separate timing mechanism sequences the shutters and filters to the photomultiplier tube and the data processing and printout. Some components of the readout section are yet to be received and installed. Microswitches sense the absence of a sample tube and interlocks cause this turntable position to be bypassed in the critical operations. The instrument automatically stops operation after the absorbances of the last sample are measured.

Measurements with this instrument surpass the precision objective of 1 to $2 \%$ relative standard deviation. For ten aliquots of a U solution, each containing $8.2 \mathrm{mg}$ of $\mathrm{U}$, an average absorbance of 0.492 was obtained with a relative standard deviation less than $0.3 \%$. Accuracy depends on wellcharacterized physical standards and the frequency with which calibrations are performed. Preliminary calibration curves indicate that the absorbance response of the instrument is linear up to $12 \mathrm{mg}$ of $U$. 'The lower practical limit is about $1 \mathrm{mg}$ of U. AS the maximum sample volume is $0.5 \mathrm{ml}$, the lower concentration limit is $2 \mathrm{mg} \mathrm{U} / \mathrm{ml}$ without preconcentration of the uranium.

Plutonium-Containing Materials for the SA LE Program

(G. C. Swanson, M. R. Ortiz, H. Kavanaugh, J. E. Rein)

The present objectives of the SALE Program, administered by the Allied Chemical Corporation, 
Idaho Chemical Programs-Operations Office, and Idaho Nuclear Corporation personnel at the National Reactor Testing Station (NRTS), are to evaluate the capability of Licensee and AEC laboratories to analyze various $U$ and $P u$ materials and to provide $U$ and $\mathrm{Pu}$ materials to the New Brunswick Laboratory for distribution as standards. Jur task in this program is to provide most of the plutonium-containing materials.

The first plutonium-containing materials to be provided are $\mathrm{Pu}\left(\mathrm{NO}_{3}\right)_{4}$ solution, $\mathrm{PuO}_{2}$ powder, $(\mathrm{U}, \mathrm{Pu}) \mathrm{O}_{2}$ powder, and $(\mathrm{U}, \mathrm{Pu}) \mathrm{O}_{2}$ pellets. The samples of the solid materials will be prepared following receipt of large lots of $\mathrm{PuO}_{2}$ from the Atlantic Richfield Hanford $\mathrm{Co}$. and of (U, Pu) $\mathrm{O}_{2}$ from Westinghouse-Hanford Co. Approximately 200 flame-sealed glass ampoules, each containing a unique amount near $0.5 \mathrm{~g}$ of $\mathrm{Pu}$ in $8 \mathrm{M} \mathrm{HNO}_{3}$, were prepared, characterized, and shipped to NRTS. The Pu in each ampoule has a unique isotopic composition at levels that are representative of the $\mathrm{Pu}\left(\mathrm{NO}_{3}\right)_{4}$ solutions transferred between facilities. These samples were prepared by adding to each ampoule weighed aliquots from each of two master standard solutions made from two, highly pure Pu metals having different isotopic compositions. The $\mathrm{Pu}$ was dissolved in $\mathrm{HBr}$, and $\mathrm{HNO}_{3}$ was added until the $\mathrm{Pu}$ content was $125 \mathrm{mg} / \mathrm{g}$ and the $\mathrm{HNO}_{3}$ molarity was 8 . The $\mathrm{HNO}_{3}$ oxidized the $\mathrm{Br}^{-}$to form $\mathrm{Br}_{2}$ which volatilized, and all of the Pu was left in the Pu(IV) state.

After the ampoules had been prepared, a small quantity of residue was observed in each. Analyses of seven samples for total $\mathrm{Pu}$ and $\mathrm{Pu}$ isotopic compositions agreed with the calculated makeup contents showing that residue formation occurred after the solutions were blended. Instructions have been provided for opening the ampoules, dissolving the residue, and effecting quantitative transfers to ensure that the total Pu can be accurately measured.

Residue formation in $\mathrm{Pu}\left(\mathrm{NO}_{3}\right)_{4}$ solutions is a chronic, world-wide, and little-understood problem that undoubtedly has contributed to many shipperreceiver differences. The preparation of $\mathrm{Pu}\left(\mathrm{NO}_{3}\right)_{4}$ solutions for use as standards is an uncertain, timeconsuming task. One more attempt is planned to prepare a stable solution, relative to both the residue formation and gas production.
Plutonium Metal Chemical Standards (R. G. Bryan, T. K. Marshall, R. R. Geoffrion)

A nother lot of $\mathrm{Pu}$ chemical standards was prepared from highly pure, low ${ }^{241} \mathrm{Pu}$ content metal purified at LASL. After extensive analyses showed thai this $\mathrm{Pu}$ metal contained less than $75 \mathrm{ppm}$ of totai impurities, approximately $600,0.5-0.6-\mathrm{g}$ samples were weighed accurately and sealed in glass ampoules in an Ar atmosphere containing less than $1 \mathrm{ppm}$ of either $\mathrm{O}_{2}$ or $\mathrm{H}_{2} \mathrm{O}$. Partial evacuation of the ampoules during the glass melting operation to form the seal further reduced the $\mathrm{O}_{2}$ and $\mathrm{H}_{2} \mathrm{O}$ concentrations and provided an internal atmosphere in which the $\mathrm{Pu}$ metal remained essentially unoxidized.

The sample weights, each certified to \pm 0.05 $\mathrm{mg}$, were checked and recorded separately by two analysts. Periodic visual examination under low power magnification for evidence of oxidation of the $\mathrm{Pu}$ was a sensitive test that screened out ampoules having faulty glass seals or other defects. Shipment of 500 of these standards to the National Bureau of Standards will be made during the next quarter. The remainder will be saved for comparison analyses on future lots and for re-analyses throughout the time the standard is being distributed.

References

1. E. Wichers, W. G. Schlect, and C. L. Gordon, "Preparing Refractory Oxides, Silicates, and Ceramic Materials for Analysis, by Heating With Acids in Sealed Tubes at Elevated Temperatures," J. Res. Nat'1. Bur. Std. 33, 451 (1944).

2. C. F. Metz and G. R. Waterbury, "Sealed-Tube Dissolution Method With Applications to Plutonium-Containing Materials, "Los Alamos Scientific Laboratory. Report LA-3554 (November 1966.)

3. W. E. Shields, National Bureau of Standards, Private Communication, 1971.

4. W. J. Maeck, G. L. Booman, M. C. Elliott, and J. E. Rein, "Spectrophotometric Extrac" tion Methods Specific for Uranium," Anal. Chem. 31, 1130 (1959).

5. W. J. Maeck, M. E. Kussy, G. L. Booman, and J. E. Rein, "Spectrophotometric Extraction Method Specific For Plutonium, "Anal. Chem. 33, 998 (1961). 